\title{
IDENTIFIKASI GULMA PADA TEGAKAN SHOREA LEPROSULA MIQ DI \\ PT. BALIKPAPAN FOREST INDUSTRIES, SOTEK, KALIMANTAN TIMUR
}

Identification of Weed Species on planted Shorea leprosula Miq. in PT. Balikpapan Forest

Industries, Sotek, East Kalimantan

\author{
Ngatiman \& Deddy Dwi Nurcahyono \\ Balai Besar Penelitian dan Pengembangan Ekosistem Hutan Dipterokarpa, Jl. AW. Syahrani No. 68, \\ Sempaja, Samarinda, Kalimantan Timur, Indonesia. \\ Telp. 0541206364, Fax. 0541742298, \\ Email:ngatimandiptero@gmail.com,deddydwi@yahoo.com
}

Diterima : 10 Februari 2016, direvisi : 25 Mei 2016, disetujui : 22 Juni 2016

\begin{abstract}
ABSTRAK
Salah satu permasalahan di lapangan dalam pengembangan jenis Shorea leprosula adalah adanya serangan gulma. Oleh sebab itu, identifikasi jenis-jenis gulma perlu dilakukan untuk dapat menentukan metode pengendaliannya. Tujuan penelitian ini adalah untuk mendapatkan data dan informasi jenis-jenis gulma pada tanaman S. leprosula. Metode yang dilakukan adalah melakukan identifikasi dan pengamatan jenis gulma yang dominan $\left(\mathrm{SDR}_{4}\right)$. Hasil penelitian menunjukkan bahwa jenis gulma yang ditemukan pada tanaman S. leprosula yaitu Alocasia tagala, Ageratum conyzoides, Alpinia sp., Bauhinia lingua, Blechnum orientale, Bridelia tomentosa, Clidemia hirta, Calathea sp., Dendrocnide stimulans, Echinocloa colonum, Erechtites valerianifolia, Eupatorium odoratum, Ficus sagittata, Globba aurantiaca, Hedyatis prostata, Hyptis capitata, Imperata cylindrica, Leea indica, Lygodium circinatum, Mikania micrantha, Paspalum conjugatum, Vernonia cinerea dan beberapa jenis lainnya. Jenis gulma yang dominan adalah $C$. hirta, M. micrantha, E. colonum dan P. conjugatum dengan nilai $\mathrm{SDR}_{4}$ masing-masing 80,12\%, 76,72\%, 67,97\% dan $63,82 \%$.
\end{abstract}

Kata kunci : gulma, identifikasi gulma, Shorea leprosula

\section{ABSTRACT}

Weed invasion is an issue on the growth of planted Shorea leprosula in the field. Identification of weed species is therefore required in order to determine appropriate control methods that should be applied. This study aims to collect data and information about weed species that attack planted S. leprosula by observing and identifying dominant weed species $\left(S D R_{4}\right)$. Result shows that weed species found on planted S. leprosula are Alocasia tagala, Ageratum conyzoides, Alpinia sp., Bauhinia lingua, Blechnum orientale, Bridelia tomentosa, Clidemia hirta, Calathea sp., Dendrocnide stimulans, Echinocloa colonum, Erechtites valerianifolia, Eupatorium odoratum, Ficus sagittata, Globba aurantiaca, Hedyatis prostata, Hyptis capitata, Imperata cylindrica, Leea indica, Lygodium circinatum, Mikania micrantha, Paspalum conjugatum, Vernonia cinerea and several other species. The dominant weed species are C. hirta, M. micrantha, E. colonum and $\mathrm{P}$. conjugatum with $\mathrm{SDR}_{4}$ value $80,12 \%, 76,72 \%, 67,97 \%$ and $63,82 \%$ respectively.

Keyword : weed, weed identification, Shorea leprosula

\section{PENDAHULUAN}

Shorea leprosula merupakan salah satu jenis tanaman cepat tumbuh dari famili Dipterocarpaceae yang berpotensi untuk dikembangkan dan direkomendasikan sebagai jenis unggulan untuk pembangunan hutan tanaman dipterokarpa (Subiakto dan Parthama, 2007). Pertumbuhan jenis tersebut dilaporkan sangat baik dibandingkan jenis-jenis meranti lainnya. Pada penanaman menggunakan sistem pengelolaan Tebang Pilih Tanam Jalur dengan teknik silvikultur intensif (TPTJ-SILIN), riap diameter mampu mencapai $1,94 \mathrm{~cm} / \mathrm{th}$
(Widiyatno et al., 2011). Konsep dasar dari silvikultur instensif tersebut adalah memadukan 3 elemen utama yaitu spesies target yang telah dimuliakan, manipulasi lingkungan dan pengendalian hama terpadu (Soekotjo, 2009). Dari pengalaman penanaman jenis-jenis dipterokarpa, masalah utama yang dihadapi adalah gangguan gulma (Subiakto et al., 2007). Gangguan gulma yang masif sangat mengkhawatirkan, karena pertumbuhannya yang cepat. Terlebih lagi pada penanaman sistem jalur dimana cahaya matahari dapat mencapai lantai hutan, maka perkembangan 
gulma dapat lebih cepat dibanding tanaman pokok berumur muda ( $<3$ tahun). Pada periode kritis ini upaya pengendalian gulma harus dilakukan intensif. Bila tidak dilakukan pengendalian maka akan menghambat pertumbuhan tanaman pokok.

Beberapa kerugian yang disebabkan serangan gulma antara lain dapat 1) menghambat pertumbuhan dan menurunnya hasil akibat persaingan dalam hal unsur hara, air, cahaya dan ruang tempat tumbuh 2) menurunkan kualitas dan hasil 3) sebagai tanaman inang bagi jasad lain 4) dapat menimbulkan keracunan bagi tanaman pokok yang dikenal sebagai alelopati 5) mempersulit pekerjaan di lapangan (Wibowo, 2006). Sebaran gulma antara satu daerah dengan daerah lainnya berbeda sesuai dengan faktor yang mempengaruhinya. Untuk keperluan pengelolaan hutan, maka jenis-jenis gulma perlu diketahui. Oleh karena itu diperlukan kegiatan inventarisasi dan identifikasi jenisjenis gulma yang terdapat pada pertanaman jenis $S$. leprosula.

Penelitian ini bertujuan untuk mengetahui jenis dan komposisi vegetasi gulma serta dominasi jenis-jenis gulma pada penerapan sistem TPTJ-SILIN dengan tanaman pokok $S$. leprosula. Informasi tentang jenis dan komposisi gulma tersebut penting untuk menentukan teknik pengendalian gulma.

\section{METODE PENELITIAN}

\section{A. Waktu dan Tempat}

Kegiatan penelitian dilaksanakan pada bulan Mei hingga Juli 2010. Lokasi kegiatan di areal penanaman TPTJ-SILIN PT. Balikpapan Forest Industries (PT. BFI). Secara administratif, lokasi termasuk dalam wilayah Kecamatan Sotek, Kabupaten Penajam Paser Utara, Provinsi Kalimantan Timur.

\section{B. Objek Penelitian}

Objek pengamatan adalah jenis-jenis gulma yang tumbuh pada jalur tanam jenis $S$. leprosula umur 1 tahun yang ditanam di hutan rawang. Tepatnya pada RKT 2008 petak 12 tahun tanam Desember 2009.

\section{Pelaksanaan Penelitian}

Dalam penelitian ini digunakan jalur tanam S. leprosula sebanyak 24 jalur. Setiap jalur terdiri dari 30 tanaman. Pengamatan identifikasi jenis gulma menggunakan intensitas sampling $10 \%$. Penentuan petak pengamatan dilakukan secara purposive sampling, yaitu pada setiap jalur diamati 3 tanaman yaitu nomor 1,15 dan 29. Dalam setiap petak pengamatan diidentifikasi kemudian dicatat nama, jumlah jenis dan jumlah individu gulma yang dijumpai.

\section{Analisis Data}

Hasil identifikasi jenis-jenis gulma yang ditemui kemudian ditabulasikan. Untuk mendapatkan informasi gulma pada suatu tempat dilakukan dengan menghitung luas penutupan tajuk dan dominasi jenis. Untuk menghitung luas tutupan tajuk, digunakan rumus (Mueller-Dumbois dan Ellenberg, 1974):

$$
\mathrm{PT}=\left\{\left(\mathrm{D}_{1}+\mathrm{D}_{2}\right) / 4\right\}^{2} \times \pi
$$

dimana :

$\mathrm{PT}=$ luas penutupan tajuk

$\mathrm{D}_{1}=$ pengukuran diameter proyeksi tajuk I

$\mathrm{D}_{2}=$ pengukuran diameter proyeksi tajuk II

$\pi \quad=3,14$

Untuk menentukan dominasi jenis gulma yang diamati digunakan rumus Numata yang dikutip Bratawinata (1987) yaitu :

$$
\mathrm{SDR}_{4}=\frac{\mathrm{N}^{\prime}+\mathrm{F}^{\prime}+\mathrm{C}^{\prime}+\mathrm{H}^{\prime}}{4} \times 100 \%
$$

dimana :

$$
\begin{aligned}
& \text { Jumlah individu } \\
& \mathrm{N}^{\prime}=\frac{\text { dari suatu jenis }}{\text { Jumlah individu }} \times 100 \% \\
& \text { dari jenis terbesar } \\
& \mathrm{F}^{\prime}=\frac{\text { Frekuensi dari suatu jenis }}{\text { Frekuensi dari jenis terbesar }} \times 100 \% \\
& \text { Jumlah luas penutupan } \\
& C^{\prime}=\frac{\text { tajuk dari suatu jenis }}{\text { Jumlah luas penutupan }} \times 100 \% \\
& \text { tajuk dari jenis terbesar } \\
& \text { Rata - rata tinggi } \\
& \mathrm{H}^{\prime}=\frac{\text { dari suatu jenis }}{\text { Rata }- \text { rata tinggi }} \times 100 \% \\
& \text { dari jenis terbesar }
\end{aligned}
$$


Data kemudian dibahas secara deskriptif terhadap beberapa jenis gulma yang dinilai berpotensi membahayakan tanaman $S$. leprosula.

\section{HASIL DAN PEMBAHASAN}

A. Jenis-Jenis Gulma

Hasil inventarisasi dan identifikasi jenisjenis gulma secara lengkap seperti yang disajikan pada Tabel 1 .

Tabel 1. Jenis-jenis gulma yang ditemukan pada plot penelitian

Table 1. Weeds type found in research plot

\begin{tabular}{|c|c|c|c|}
\hline No. & Famili & $\begin{array}{l}\text { Jumlah } \\
\text { jenis }\end{array}$ & Jenis gulma \\
\hline 1 & Araceae & 2 & Alocasia tagala, Raphidophora $s p$ \\
\hline 2 & Asteraceae & 6 & $\begin{array}{l}\text { Ageratum conyzoides, Blumea riparia, Erechtites valerianifolia, } \\
\text { Eupatorium odoratum, Mikania micrantha, Vernonia cinerea }\end{array}$ \\
\hline 3 & Blechnaceae & 2 & Blechnum orientale, Millettia sericea \\
\hline 4 & Convolvulaceae & 1 & Merremia umbellata \\
\hline 5 & Cyperaceae & 1 & Scleria puspurascens \\
\hline 6 & Dennstaedtiaeae & 2 & Microlepia manilensis, Microlepia speluncae \\
\hline 7 & Dilleniaceae & 1 & Tetracera scandens \\
\hline 8 & Euphorbiaceae & 9 & $\begin{array}{l}\text { Bridelia glauca, Bridelia tomentosa, Corymborchis veratrifolia, } \\
\text { Macaranga gigantea, Macaranga hypoleuca, Macaranga tanarius, } \\
\text { Macaranga triloba, Thespesia populnea, Trigonostemon sp }\end{array}$ \\
\hline 9 & Fabaceae & 2 & Bauhinia lingua, Mimosa pudica, Sesbania sesban \\
\hline 10 & Gleicheniaceae & 1 & Gleichenia linearis \\
\hline 11 & Lamiaceae & 1 & Hyptis capitata \\
\hline 12 & Leeaceae & 1 & Leea indica \\
\hline 13 & Lycopodiaceae & 1 & Lycopodium cernuum \\
\hline 14 & Marantaceae & 1 & Calathea $s p$ \\
\hline 15 & Melastomaceae & 3 & Clidemia hirta, Clidemia sp, Melastoma malabatrichum \\
\hline 16 & Moraceae & 1 & Ficus sagittata \\
\hline 17 & Nephrolepidaceae & 1 & Nephrolepis falcata \\
\hline 18 & Pandanaceae & 1 & Pandanus sp \\
\hline 19 & Piperaceae & 2 & Peperomia pellucida, Piper aduncum \\
\hline 20 & Poaceae & 4 & $\begin{array}{l}\text { Centotheca lappacea, Echinocloa colonum, Imperata cylindrica, } \\
\text { Paspalum conjugatum }\end{array}$ \\
\hline 21 & Rhizophoraceae & 1 & Carallia brachiata \\
\hline 22 & Rosaceae & 1 & Rubus moluccanus \\
\hline 23 & Rubiaceae & 5 & $\begin{array}{l}\text { Hedyotis prostata, Lasianthus tomentosus, Ophiorriza canescens, } \\
\text { Timonius flavescens, Uncaria cordota }\end{array}$ \\
\hline 24 & Rutaceae & 1 & Evodia sp \\
\hline 25 & Sapindaceae & 1 & Cardiospermum halicacabum \\
\hline 26 & Schizaeaceae & 2 & Lygodium circinatum, Lygodium microphyllum \\
\hline 27 & Scrophulariaceae & 1 & Mazus japonicus \\
\hline 28 & Selaginellaceae & 2 & Selaginella sp, Selaginella willdenovii \\
\hline 29 & Smilacaceae & 1 & Smilax modesta \\
\hline 30 & Solanaceae & 1 & Solanum torvum \\
\hline 31 & Urticaceae & 1 & Dendrocnide stimulans \\
\hline 32 & Verbenaceae & 1 & Callicarpa longifolia \\
\hline 33 & Zingiberaceae & 3 & Alpinia sp, Globba aurantiaca, Globba sp \\
\hline
\end{tabular}

Sumber: diolah dari data primer

Secara keseluruhan terdapat 65 jenis yang teridentifikasi gulma dan termasuk dalam 33 famili. Dua famili dengan jenis terbanyak adalah famili Euphorbiaceae sebanyak 9 jenis kemudian diikuti famili Asteraceae sebanyak 6 jenis. Gulma yang termasuk dalam golongan gulma berdaun lebar (broadleaves) sangat mendominasi yaitu sebanyak 92,31\%, kemudian gulma rumput-rumputan (grasses) sebanyak $6,15 \%$ dan gulma golongan tekian (sedges) sebanyak 1,54\%. Gulma yang termasuk rumput-rumputan yaitu Centotheca lappacea, Echinocloa colonum, Imperata cylindrica dan Paspalum conjugatum, gulma 
tekian yaitu Scleria puspurascens, sedangkan jenis gulma lainnya termasuk gulma berdaun lebar.

Keanekaragaman jenis gulma yang ditemui di PT. BFI tergolong tinggi apabila dibandingkan dengan beberapa lokasi lainnya seperti di Lahat Sumatera Selatan 20 jenis dari 9 famili (Imanullah et al., 2013b), Bengkulu 33 jenis dari 14 famili (Imanullah et al., 2013a), Simalungun Sumatera Utara 39 jenis dari 15 famili (Faisal et al., 2013) dan Banyuasin Sumatera Selatan 18 jenis dari 11 famili (Kurniawan et al, 2015). Jika membandingkan data yang ada, tampak bahwa pulau Kalimantan memiliki keanekaragaman jenis gulma yang lebih tinggi dibandingkan pulau Sumatera. Distribusi sebaran jenis gulma juga tidak sama antar wilayah. Jenis-jenis gulma yang ditemui baik itu terdapat di Sumatera maupun Kalimantan (plot PT. BFI) adalah Ageratum conyzoides, Borreria laevis, Clidemia hirta, Erechtites valerianifolia, Imperata cylindrica, Melastoma malabatrichum, Mikania micrantha, Mimosa pudica dan Paspalum conjugatum (Imanullah et al., 2013a; Imanullah et al., 2013b; Faisal et al., 2013; Kurniawan et al, 2015).

Dari keseluruhan jumlah jenis yang ada di lokasi pengamatan, terdapat 12 jenis gulma yang sudah sangat umum ditemukan di hutan tanaman. Beberapa jenis diantaranya harus dikendalikan dan diberantas. Dua jenis yang tergolong berbahaya bagi tanaman pokok dan harus dimusnahkan adalah $M$. micrantha dan $I$. cylindrica, selain itu terdapat 5 jenis lainnya yang perlu dikendalikan (Tabel 2).

Tabel 2. Tabel toleransi tanaman terhadap beberapa gulma

Table 2. Plant toleration table to some weeds attack

\begin{tabular}{|c|c|}
\hline Jenis gulma & Kategori \\
\hline Ageratum conyzoides & $\mathrm{B}$ \\
\hline Mikania micrantha & $\mathrm{E}$ \\
\hline Blechnum orientale & $\mathrm{B} / \mathrm{C}$ \\
\hline Merremia umbellata & $\mathrm{D}$ \\
\hline Scleria puspurascens & $\mathrm{D}$ \\
\hline Mimosa pudica & $\mathrm{D}$ \\
\hline Hyptis capitata & $\mathrm{D}$ \\
\hline Clidemia hirta & $\mathrm{D}$ \\
\hline Imperata cylindrica & $\mathrm{E}$ \\
\hline Paspalum conjugatum & $\mathrm{C}$ \\
\hline Cardiospermum halicacabum & $\mathrm{C}$ \\
\hline Selaginella willdenovii & $\mathrm{B} / \mathrm{C}$ \\
\hline
\end{tabular}

Sumber : Tjitrosemito dan Kasno (1998) dalam Wibowo (2006)

Keterangan :

B : Vegetasi yang tidak merugikan; gulma semusim, mati setelah berbunga

C : Vegetasi tahunan, disebut juga soft grasses, umumnya bermanfaat sebagai penutup tanah, dalam keadaan berlebihan perlu dikurangi

D : Vegetasi semak menahun, umumnya merugikan, perlu dikendalikan

E : Vegetasi yang harus diberantas

\section{B. Dominasi Gulma}

Empat rangking teratas jenis gulma dominan berdasarkan nilai $\mathrm{SDR}_{4}$ dari masingmasing jalur disajikan pada Tabel 3 (Lampiran). Jenis gulma dengan dominasi tertinggi adalah C. hirta (80,12\%), $M$. micrantha $(76,72 \%)$, E. colonum $(69,97 \%)$ dan P. conjugatum $(63,82 \%)$. Empat gulma dominan tersebut seperti pada Gambar 1.
C. hirta (akar kala) merupakan tumbuhan perdu tahunan, gulma yang tangguh, perakaran kuat dan dalam, batangnya keras dan bila ditebas akan tumbuh tunas-tunas baru. Gulma ini tumbuh pada tanah yang lembab atau agak kering, lokasi terbuka atau ternaung, berbunga sepanjang tahun serta sebarannya meliputi 5-1.350 m dpl (Faisal, 2013). 


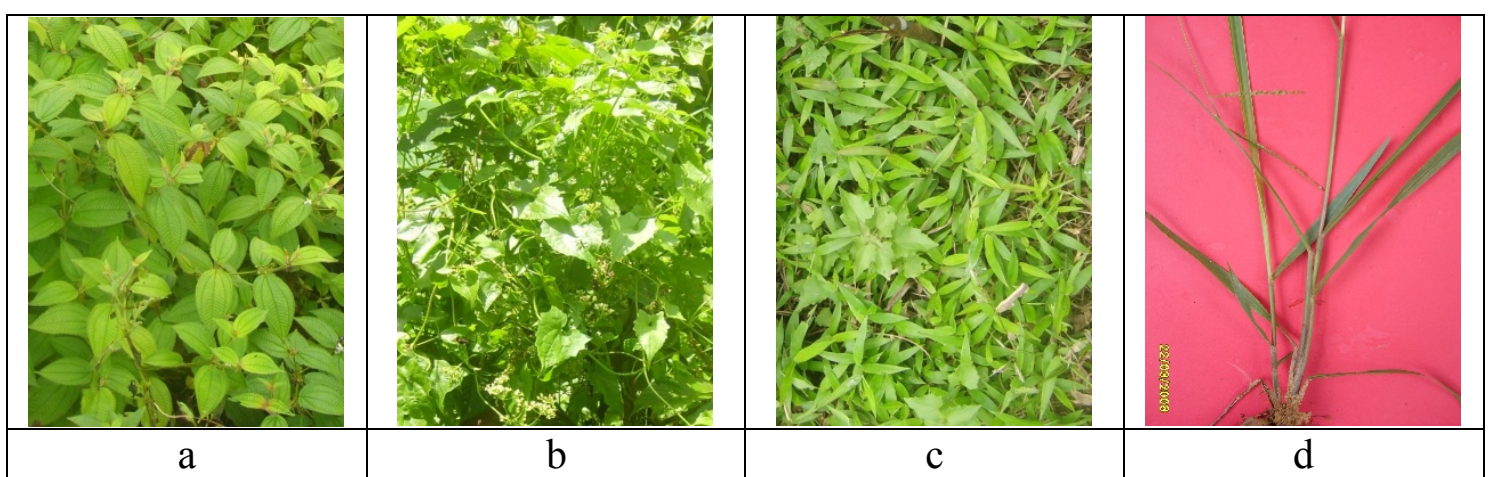

Gambar 1. Jenis-jenis gulma dominan (a) C. hirta, (b) M. micrantha, (c) E. colonum dan (d) P. conjugatum Figure 1. Dominant weeds type (a) C. hirta, (b) M. micrantha, (c) E. colonum and (d) P. conjugatum

Untuk wilayah Asia Tenggara C. hirta tersebar di Indonesia, Singapura, Brunei, Thailand dan Malaysia. Disamping itu, sebaran $C$. hirta mencakup juga wilayah Papua New Guinea, India, Australia dan Tanzania (Breaden et al, 2012).

Berdasarkan pengamatan di lapangan, $C$. hirta hampir ditemukan di seluruh areal penelitian. Tumbuhan tersebut tidak melilit. Namun, yang menjadi permasalahan adalah apabila dalam jumlah banyak dapat mempengaruhi pertumbuhan tanaman $S$. leprosula terutama bila tanaman $S$. leprosula lebih rendah dari $C$. hirta. Sebaliknya, bila tanaman S. leprosula lebih tinggi dari C. hirta, pertumbuhan $S$. leprosula tidak terlalu terpengaruh namun tetap dikendalikan.

M. micrantha (sembung rambat) merupakan spesies yang termasuk kelompok gulma yang mudah menginvasi suatu lahan (invided weed). Jenis ini memiliki kemampuan tumbuh dan menyebar yang tinggi. Memperbanyak diri dengan memproduksi biji yang sangat banyak (Tjitrosemito et al, 2007) maupun dengan merundukkan bagian nodusnya ke tanah.

Hasil pengamatan di lapangan menunjukkan bahwa $M$. micrantha adalah gulma yang paling potensial mengakibatkan kerusakan pada tanaman. M. micrantha melilit batang $S$. leprosula dan berkembang hingga tajuk tanaman. Karena pertumbuhan gulma yang cepat, tajuk tidak mampu menopang biomassa gulma sehingga batang menjadi melengkung, patah dan akhirnya tanaman mati. Kemampuan M. micrantha untuk merambat naik akan semakin berkurang seiring dengan peningkatan diameter tanaman pokok (Hu dan Li, 2014). Tanaman pokok $S$. leprosula yang diamati masih berumur 1 tahun dengan diameter yang masih kecil sehingga dengan mudah dililit dan dirambat oleh $M$. micrantha hingga tajuk teratas.

Akibat kerusakan yang ditimbulkan dan hingga menyebabkan kematian pada tanaman pokok, maka M. micrantha dikategorikan kedalam gulma yang harus diberantas (Wibowo, 2006; Goosem, 2008). Kerusakan pada tanaman pokok yang timbul akibat gangguan $M$. micrantha sejalan dengan pengalaman Tjitrosemito et al, (2007) di beberapa lokasi HPH di Indonesia. Selain di Indonesia, invasi $M$. micrantha juga terdapat di beberapa negara lain seperti India (Tripathi, 2012) dan Papua New Guinea (Day et al, 2012).

Disamping adanya gangguan lilitan, $M$. micrantha merupakan salah satu gulma yang dapat mengeluarkan zat alelokimia. Zat tersebut menghambat pertumbuhan tanaman pokok dimana prosesnya dinamakan alelopati (Sembodo, 2010).

Lebih lanjut bahwa terdapat variasi antara daun dan akar $M$. micrantha terhadap pengaruh alelopati di bawah tanah. Hasil percobaan yang dilakukan Wu et al (2009) menunjukkan bahwa pengaruh alelopati di bawah tanah oleh akar M. micrantha kemungkinan lebih kuat dibandingkan daun untuk beberapa jenis tanaman dan pengaruh alelopati dari daun M. micrantha dapat juga lebih kuat dibandingkan akar pada jenis yang lain, setidaknya berpengaruh pada pertumbuhan akar jenis lain tersebut.

$P$. conjugatum (rumput pait) merupakan jenis gulma rumput-rumputan yang umurnya tahunan. Jenis ini semula berasal dari Brasilia dan kini telah menyebar luas di Indonesia. 
Tinggi tanaman mulai dari 20-75 $\mathrm{cm}$. Sebarannya di dataran rendah hingga ketinggian $1.700 \mathrm{~m} \mathrm{dpl,} \mathrm{di} \mathrm{tanah} \mathrm{yang} \mathrm{tidak}$ terlalu kering dan mampu hidup pada tempat ternaung maupun terbuka (Heyne, 1987).

\section{KESIMPULAN DAN SARAN}

\section{A. Kesimpulan}

Komposisi vegetasi gulma yang ditemukan di sekitar tegakan $S$. leprosula pada RKT 2008 petak 12 tahun tanam Desember 2009 PT. BFI terdiri dari 65 jenis yang termasuk dalam 33 famili. Empat jenis gulma yang dominan yaitu $C$. hirta, $M$. micrantha, $E$. colonum dan $P$. conjugatum.

\section{B. Saran}

Perlu tindakan pengendalian gulma di sekitar tegakan $S$. leprosula agar tanaman pokok dapat tumbuh baik. M. micrantha merupakan salah satu jenis gulma mematikan sehingga perlu diberantas.

\section{DAFTAR PUSTAKA}

Bratawinata A.A., (1987). Komposisi dan Dominasi Jenis Pada Hutan Primer Bekas Kebakaran di Hutan Pendidikan UNMUL Taman Hutan Raya Bukit Soeharto. Proyek Peningkatan Perguruan Tinggi Universitas Mulawarman. Samarinda

Breaden, R.C., S.J. Brooks dan H.T. Murphy. (2012). The Biology of Australia Weeds 59. Clidemia Hirta (L.) D. Don. Plant Protection Quarterly Vol. 27 (1) : 3-18

Day, M.D., A. Karvi, K. Kurika, C.F. Dewhurst, S. Waisale, J. Saul-Maora, J. Fidelis, J. Bokosou, J. Moxon, W. Orapa dan K.A.D. Senaratne. (2012) Mikania micrantha Kunth (Asteraceae) (Miel-aminute) : Its Distribution and Physical and Socioeconomic Impacts in Papua New Guinea. Pacific Science 66 (2) : 213-223

Faisal, R., E. B. M. Siregar dan N. Anna. (2013). Inventarisasi Gulma Pada Tegakan Tanaman Muda Eucalyptus spp. Peronema Forestry Science Journal 2 (2) : 44-49

Goosem, F. (2008). Invasive Weeds In The Wet Tropics. In Stork, N. E. dan S.M. Turton (Eds). Living in a Dynamic Tropical Forest Landscape. Blackwell Publishing : 307-321

Heyne, K. (1987). Tumbuhan Berguna Indonesia Jilid I. Yayasan Sarana Wana Jaya. Jakarta : 207

$\mathrm{Hu}$, L. dan M. Li. (2014). Climbing Capacity of the Invasive Vine Mikania micrantha Kunth on Vertical Artificial Poles. Biol Invasions 16 : 295302
Imanullah, A., A. Kurniawan, Asmaliyah dan N. Andriani. (2013a). Komposisi dan Jenis Gulma di Bawah Tegakan Kayu Bawang (Dysoxylum mollissimum Blume) di Provinsi Bengkulu. Prosiding Seminar Hasil Penelitian Balai Penelitian Kehutanan "Integrasi IPTEK Dalam Kebijakan dan Pengelolaan Hutan Tanaman di Sumatera Bagian Selatan. Pusat Litbang Peningkatan Produktivitas Hutan : 179-192

Imanullah, A., S. Utami dan Asmaliyah. (2013b). Dominasi dan Status Potensi Gulma Pada Jenis Bambang Lanang (Michelia campaka L.). Prosiding Seminar Hasil Penelitian Balai Penelitian Kehutanan "Integrasi IPTEK Dalam Kebijakan dan Pengelolaan Hutan Tanaman di Sumatera Bagian Selatan. Pusat Litbang Peningkatan Produktivitas Hutan : 193-200

Kurniawan, A., E. Yuliana dan A. Imanullah. (2015). Struktur dan Komposisi Gulma di Bawah Tegakan Tanaman Kayu Bawang. Prosiding Seminar Nasional Silvikultur II: Pembaruan Silvikultur Untuk Mendukung Pemulihan Fungsi Hutan Menuju Ekonomi Hijau, Yogyakarta 24 Agustus 2014. UGM Yogyakarta : 665-671

Mueller-Dombois, D. dan H. Ellenberg. (1974). Aims and method of vegetation ecology. John Wiley \& Sons Inc. Toronto

Sembodo, D.R.J. (2010). Gulma dan Pengelolaannya. Graha Ilmu. Yogyakarta

Soekotjo. (2009). Teknik Silvikultur Intensif (SILIN). Gadjah Mada University Press. Yogyakarta

Subiakto, A. dan P. Parthama. (2007). Pemilihan Jenis dan Biaya Penanaman Dipterokarpa. Info Teknis Dipterokarpa. 1 (1) : 1-6

Subiakto, A., R. Effendi dan Ernayati. (2007). Ketersediaan IPTEK Pembibitan, Penanaman dan Pemeliharaan Hutan Tanaman Dipterokarpa. Seminar Pengembangan Hutan Tanaman Dipterokarpa dan Ekspose TPTII/SILIN. Balai Besar Penelitian Dipterokarpa. Samarinda : 17-27

Tjitrosemito, S, G. Rahayu dan K. Martosentono. (2007). Potensi dan Pencegahan Hama dan Penyakit Hutan Tanaman di Indonesia. Seminar Pengembangan Hutan Tanaman Dipterokarpa dan Ekspose TPTII/SILIN. Balai Besar Penelitian Dipterokarpa. Samarinda : 29-56

Tripathi, R.S., M.L. Khan dan A.S. Yadav. (2012). Biology of Mikania micrantha H.B.K. : a Review. In J.R. Bhattm J.S.Singh, S.P. Singh, R.S. Tripathi dan R.K. Kohli (Eds). Invasive Alien Plants : An Ecological Appraisal for the Indian Subcontinent. CAB International : 99-107.

Wibowo, A. (2006). Gulma di Hutan Tanaman dan Upaya Pengendaliannya. Pusat Penelitian dan Pengembangan Hutan Tanaman. Badan Penelitian dan Pengembangan Kehutanan. Bogor 
Widiyatno, Soekotjo, M. Naiem, S. Hardiwinoto dan S. Purnomo. (2011). Pertumbuhan Meranti (Shorea spp.) Pada Sistem Tebang Pilih Tanam Jalur Dengan Teknik Silvikultur Intensif (TPTJ-SILIN). Jurnal Penelitian Hutan dan Konservasi Alam. Vol. 8 (4) : 373-383
Wu, A.P, H. Yu. S.Q. Gao, Z.Y Huang, W.M. He, S.L. Miao dan M. Dong. (2009). Differential Belloground Allelopathic Affects of Leaf and Root of Mikania micrantha. Trees Structure and Function $23: 11-17$ 


\section{Lampiran :}

Tabel 3. Empat rangking teratas jenis-jenis gulma dominan berdasarkan Nilai Sum of Dominance Ratio $\left(\mathrm{SDR}_{4}\right)$

Table 3. Rank of dominance level of each species based on Sum of Dominance Ratio (SDR 4 )

\begin{tabular}{|c|c|c|c|c|c|}
\hline $\begin{array}{l}\text { No. } \\
\text { Jalur }\end{array}$ & Jenis gulma & $\mathrm{SDR}_{4}$ & $\begin{array}{l}\text { No. } \\
\text { Jalur }\end{array}$ & Jenis gulma & $\mathrm{SDR}_{4}$ \\
\hline \multirow[t]{4}{*}{1.} & Mikania micrantha & 100,00 & 13. & M. micrantha & 87,36 \\
\hline & 2. $\quad$ Corymborchis veratrifolia & 41,73 & & 2. C. hirta & 82,68 \\
\hline & 3. $\quad$ Clidemia hirta & 39,49 & & 3. M. speluncae & 46,23 \\
\hline & 4. Leea indica & 26,23 & & 4. H. capitata & 37,17 \\
\hline \multirow[t]{4}{*}{2.} & 1. M. micrantha & 94,23 & 14. & 1. Centhoteca lappacea & 91,89 \\
\hline & 2. Echinocloa colonum & 65,20 & & 2. C. hirta & 75,38 \\
\hline & 3. C. hirta & 52,61 & & 3. E. odoratum & 63,52 \\
\hline & 4. Hyptis capitata & 21,85 & & E. colonum & 61,50 \\
\hline \multirow[t]{4}{*}{3.} & 1. M. micrantha & 100,00 & 15. & C. hirta & 100,00 \\
\hline & 2. Alpinia sp. & 74,22 & & 2. P. aduncum & 78,23 \\
\hline & 3. C. hirta & 53,70 & & 3. M. micrantha & 77,98 \\
\hline & 4. L. indica & 36.10 & & 4. P. conjugatum & 53,09 \\
\hline \multirow[t]{4}{*}{4.} & 1. C. hirta & 90,62 & 16. & 1. C. hirta & 89,23 \\
\hline & 2. M. micrantha & 63,42 & & 2. P. conjugatum & 67,07 \\
\hline & 3. $\quad$ Paspalum conjugatum & 60,24 & & 3. Bridelia tomentosa & 55,87 \\
\hline & 4. Rubus moluccanus & 44,06 & & 4. M. micrantha & 54,89 \\
\hline \multirow[t]{4}{*}{5.} & 1. M. micrantha & 73,88 & 17. & 1. C. hirta & 98,97 \\
\hline & 2. Euphatorium odoratum & 61,12 & & 2. M. micrantha & 89,56 \\
\hline & 3. Piper aduncum & 53,27 & & H. capitata & 78,87 \\
\hline & 4. Sesbania sesban & 48,51 & & 4. Scleria puspurascens & 65,00 \\
\hline \multirow[t]{4}{*}{6.} & 1. H. capitata & 63,16 & 18. & 1. C. hirta & 83,12 \\
\hline & 2. M. micrantha & 55,99 & & 2. E. odoratum & 77,17 \\
\hline & 3. C. hirta & 48,15 & & 3. M. micrantha & 76,98 \\
\hline & 4. Mazoz japonicus & 47,14 & & 4. P. conjugatum & 74,23 \\
\hline \multirow[t]{4}{*}{7.} & 1. M. micrantha & 89,41 & 19. & 1. C. hirta & 89,76 \\
\hline & 2. C. hirta & 57,24 & & 2. P. conjugatum & 82,34 \\
\hline & 3. E. odoratum & 56,15 & & 3. M. micrantha & 58,02 \\
\hline & 4. Microlepia speluncae & 42,42 & & 4. E. colonum & 41,03 \\
\hline \multirow[t]{4}{*}{8.} & 1. $\quad$ C. hirta & 92,91 & 20. & 1. M. micrantha & 78,56 \\
\hline & 2. M. micrantha & 55,98 & & 2. P. conjugatum & 65,09 \\
\hline & 3. P. aduncum & 55,83 & & 3. L. indica & 58,78 \\
\hline & 4. $\quad$ E. colonum & 47,46 & & 4. C. hirta & 46,90 \\
\hline \multirow[t]{4}{*}{9.} & 1. C. hirta & 100,00 & 21. & 1. C. hirta & 93,23 \\
\hline & 2. E. colonum & 44,61 & & M. manilensis & 67,20 \\
\hline & 3. M. micrantha & 44,60 & & 3. Calathea $\mathrm{sp}$. & 34,00 \\
\hline & 4. Macaranga gigantea & 39,68 & & 4. Thespesia populnea & 29,98 \\
\hline \multirow[t]{4}{*}{10.} & 1. C. hirta & 83,43 & 22. & 1. C. hirta & 100,00 \\
\hline & 2. Calathea $\mathrm{sp}$. & 79,48 & & 2. M. micrantha & 89,56 \\
\hline & 3. Alocasia $\mathrm{sp.}$ & 54,75 & & 3. Calathea sp. & 67,90 \\
\hline & 4. Selaginella sp. & 39,99 & & E. colonum & 54,23 \\
\hline \multirow[t]{4}{*}{11.} & 1. C. hirta & 84,95 & 23. & M. micrantha & 83,09 \\
\hline & 2. M. micrantha & 80,31 & & 2. Calathea sp. & 64,21 \\
\hline & 3. P. conjugatum & 67,50 & & 3. P. conjugatum & 63,70 \\
\hline & $4 \quad$ M. speluncae & 46,93 & & $\begin{array}{ll}\text { 4. } & \text { M. gigantea } \\
\end{array}$ & 34,99 \\
\hline \multirow[t]{4}{*}{12.} & 1. C. hirta & 85,07 & 24. & 1. E. colonum & 93,62 \\
\hline & 2. M. micrantha & 78,38 & & 2. E. odoratum & 61,42 \\
\hline & 3. $\quad$ M. gigantea & 65,83 & & 3. P. conjugatum & 59,46 \\
\hline & 4. P. conjugatum & 45,51 & & 4. C. hirta & 35,11 \\
\hline
\end{tabular}

